\title{
4-hydroxynonenal protein adducts: Key mediator in Rett syndrome oxinflammation
}

\author{
Giuseppe Valacchi $^{\mathrm{a}, \mathrm{b}, *, 1}$, Alessandra Pecorelli ${ }^{\mathrm{a}, \mathrm{b}, 1}$, Carlo Cervellati ${ }^{\mathrm{c}}$, Joussef Hayek ${ }^{\mathrm{d}}$ \\ a Plants for Human Health Institute, Department of Animal Sciences, NC State University, NC Research Campus, 600 Laureate Way, Kannapolis, NC 28081, USA \\ b Department of Life Sciences and Biotechnology, University of Ferrara, Via Luigi Borsari 46, 44121 Ferrara, Italy \\ ${ }^{\mathrm{c}}$ Department of Biomedical and Specialist Surgical Sciences, Section of Medical Biochemistry, Molecular Biology and Genetics, University of Ferrara, Via Luigi Borsari 46, \\ 44121 Ferrara, Italy \\ d Child Neuropsychiatry Unit, University Hospital, AOUS, Viale Mario Bracci, 53100 Siena, Italy
}

\section{A R T I C L E I N F O}

\section{Keywords:}

Inflammation

Isoprostanes

Oxidative stress

Rare disease

Orphan disease

CDKL5

FOXG1

$\mathrm{MecP} 2$

\begin{abstract}
A B S T R A C T
In the last 15 years a strong correlation between oxidative stress (OxS) and Rett syndrome (RTT), a rare neurodevelopmental disorder known to be caused in $95 \%$ of the cases, by a mutation in the methyl-CpG-binding protein 2 (MECP2) gene, has been well documented. Here, we revised, summarized and discussed the current knowledge on the role of lipid peroxidation byproducts, with special emphasis on 4-hydroxynonenal (4HNE), in RTT pathophysiology. The posttranslational modifications of proteins via 4HNE, known as 4HNE protein adducts (4NHE-PAs), causing detrimental effects on protein functions, appear to contribute to the clinical severity of the syndrome, since their levels increase significantly during the subsequent 4 clinical stages, reaching the maximum degree at stage 4, represented by a late motor deterioration. In addition, 4HNE-PA are only partially removed due to the compromised functionality of the proteasome activity, contributing therefore to the cellular damage in RTT. All this will lead to a characteristic subclinical inflammation, defined "OxInflammation", derived by a positive feedback loop between OxS byproducts and inflammatory mediators that in a long run further aggravates the clinical features of RTT patients. Therefore, in a pathology completely orphan of any therapy, aiming $4 \mathrm{HNE}$ as a therapeutic target could represent a coadjuvant treatment with some beneficial impact in these patients.
\end{abstract}

\section{Introduction}

\subsection{Rett syndrome}

Rett syndrome (RTT) is a rare and debilitating neurological disorder that affects approximately one in every $10,000 / 15,000$ females and is only rarely observed in males [1]. A typical aspect of RTT is a phase of normal development for 6-18 months after birth, followed by a stagnation and a delayed onset of symptoms with progressive loss of milestones and cognitive disability. In particular, the characteristic disease progression, which evolved in four clinical stages, leads to a myriad of typical signs, including overall growth retardation, loss of speech and motor functions, such as loss of hand skills and development of stereotypical hand movements. In addition, affected patients typically show social interaction deficits as well as autism-like traits; besides, some features such as microcephaly, breathing irregularities and apneas, heart problems, gastrointestinal abnormalities, seizures, scoliosis, abnormal sleep patterns and early hypotonia are also common [2].

Most cases of "classic" or "typical" RTT ( $>96 \%$ ) are caused by de novo mutations in the X-linked gene MECP2 and arise in germ cells, usually of the paternal origin $[3,4]$. Due on the type, location and severity of the genetic mutations and balance of X-inactivation, RTT shows a wide range of phenotypic outcomes, ranging from mild to extremely severe clinical presentations $[5,6]$. Loss-of-function mutations in MECP2 are also responsible for several other conditions, included in the MECP2 Spectrum Disorders, such as severe neonatal encephalopathy, bipolar disorder, schizophrenia, Angelman-like syndrome, mental retardation, and autism [7-9]. According to the new revised criteria [10], patients with nonclassic phenotypes are considered to have "variant" or "atypical" forms of RTT, including: "Preserved Speech Variant" (PSV), also caused by MECP2 mutation and characterized by milder clinical abnormalities and by the appearance of some degree of speech [11]; "Early Seizure Variant" and "Congenital

\footnotetext{
* Correspondence to: Dept. of Animal Science, North Carolina State University, Plants for Human Health Institute, NC Research Center, 28081 Kannapolis, NC, USA.

E-mail addresses: giuseppe.valacchi@unife.it, gvalacc@ncsu.edu (G. Valacchi).

${ }^{1}$ Equally contributed.
} 
Variant", known to be caused by mutations in other loci, i.e. CDKL5 and FOXG1, and characterized by unique features, as early infantile seizures and congenital onset [12,13]. Among RTT atypical forms, for their specific gene mutations and peculiar clinical features, the two variants CDKL5 and FOXG1 are hence considered as distinct clinical and molecular entities [14].

The epigenetic factor MeCP2 binds to methylated cytosines in target gene promoters and, interacting with other co-factors, is involved in the regulation of their transcription as both repressor or activator [15-17]. More recent evidence shows that MeCP2 can also influence alternative splicing of downstream gene products, expression of various microRNAs and long non-coding RNAs as well as act like a chromatinremodeling protein, triggering the chromatin compaction at methylated DNA sites with consequent regulation of the transcription of adjacent genes [18]. Although the protein is ubiquitously transcribed among various tissues, its levels appear higher in the brain, in particular in neurons, where it plays an essential role not only in neuronal maturation, dendritic arborization and synaptogenesis, but also in maintaining mature neuronal networks and electrophysiological responses throughout life [19-22].

In addition, recent studies have also reported the presence of MeCP2 in all glial cell types including astrocytes, oligodendrocyte progenitor cells and oligodendrocytes [23-27] and, to date, it is well clear that MeCP2 deficiency in both neurons and glia can have a profound impact on brain function and contribute to manifestation of specific RTT symptoms [21,28], while the restoration of Mecp2 in astrocytes can improve some of these manifestations including locomotion defects, anxiety levels, and respiratory abnormalities, greatly prolonging lifespan in Mecp2-deficient mouse models [25,26,29,30].

The wide variety of MeCP2 functions clearly points out how complex can be the range of possible mechanisms leading from the gene mutations to the RTT phenotypes. In light of the recent insights, a new scenario is emerging in which neurons start and direct the pathology in connection with the dysfunction of other cell types and peripheral tissues which, exacerbating some symptoms, can contribute to further amplify neurologic problems, ultimately, accomplishing a positive feedback loop. However, while the structure, functions, interactions and expression of MeCP2 have been widely explored and a number of their aspects has been revealed, much about this protein with pleiotropic actions remains yet to be discovered.

\subsection{Evidences of redox imbalance in RTT}

Compelling evidences point out the possible role of oxidative stress (OxS) as a player in the pathogenic mechanisms of RTT [31-33]. Based on a number of reports, the redox imbalance is a peculiar condition that occurs in both RTT patients and RTT animal models [34,35]. A close relationship between the different clinical stages/phenotypes of the syndrome and the OxS levels has been well recognized in RTT patients [36-39]. In RTT mice, the increased brain oxidative damage appears as an event that precedes the onset of the hallmark features of the disease, suggesting that Mecp2 protein deficiency and aberrant redox homeostasis could be inextricably linked to each other [35].

Disturbances of the normal redox status in RTT can arise from either oxidants overproduction and impaired antioxidant defense system. While the precise cascade of the molecular events linking the MECP2 mutation to the oxidative imbalance remain yet little decipherable, now there are increasing evidences that mitochondrion can represent the initial source of oxidants production in RTT, as consequence of its dysfunction [32,40-43]. In addition to mitochondria, also NADPH oxidase (NOX) activation appears as a source of endogenous OxS, able to play a possible role in RTT patients oxidative damage (Fig. 1) [44].

A wide number of studies, both in cellular and tissue samples from murine models and patients, clearly demonstrated the mitochondrial dysfunction in RTT. Since the late 80's and also more recently, several reports showed the presence of mitochondrial ultrastructural abnorm-

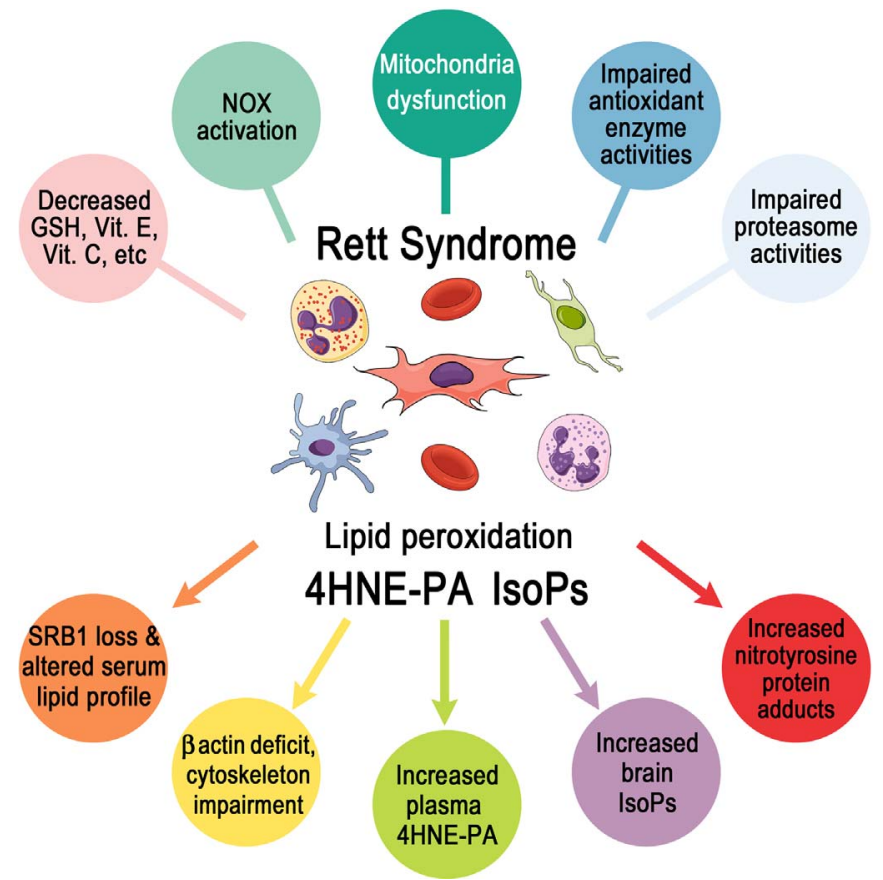

Fig. 1. Redox imbalance as a contributing factor to the pathomechanisms of Rett syndrome. Disturbances of the redox homeostasis in RTT arise from either oxidants overproduction and impaired antioxidant defence system. A wide number of studies, both in cells and tissues from patients and mouse models, clearly demonstrated, among others, mitochondrial dysfunction, NADPH oxidase (NOX) activation, low levels of GSH and other antioxidants, impaired antioxidant enzyme activities, and reduced proteasome activities. Overall, these defective molecular processes are able to cause OxS, leading to oxidative damage including increased plasma and cell levels of 4HNE-PA, loss of HDL receptor SRB1 and altered serum lipid profile, impairment of cytoskeleton proteins, increased IsoPs and nitrotyrosine protein adducts levels.

alities in biopsies of brain, liver, muscle and skin as well as in peripheral blood mononuclear cells (PBMC) from subjects affected by RTT. The mitochondrial morphological changes consisted in swollen organelles with vacuolization, granular inclusions and membranous changes [4556]. Ultrastructural analyses of brain, muscle and microglia isolated from Mecp2-null mice identified widespread abnormal "dissolving" features of mitochondria; in particular, most mitochondria were enlarged, dysmorphic and had electron-lucent central matrices and non-parallel, disorganized cristae, confirming the results obtained in human studies [57-59].

In parallel to structure abnormalities, alterations in the activity of mitochondrial respiratory chain complexes associated to impaired energy metabolism have been also detected in both RTT patients and animal models [44,52,59-68].

In addition, recent studies on gene expression profile revealed abnormalities in several genes related to mitochondrial function and/ or structure in frontal cortex and PBMC from RTT patients $[56,69]$. Using a Mecp2-null mouse model, Kriaucionis et al. [62] demonstrated the overexpression of gene for ubiquinol-cytochrome $\mathrm{c}$ reductase core protein 1 (Uqcrc1), which encodes for a subunit of mitochondrial respiratory complex III, with an increase in complex III activity and a decrease in that of complex IV. Another gene for a component of complex IV, cytochrome c oxidase subunit 1 (CO1), was also downregulated in the frontal cortex of RTT patients [64] and in the skeletal muscle of the symptomatic Mecp2 $2^{\mathrm{y} /-}$ mice [66]. In addition, a microarray study on PBMC from RTT patients reported an up-regulation of several mitochondria-related genes. Specifically, the most significantly regulated transcripts included those encoding for several subunits of mitochondrial respiratory chain complexes and thus linked directly to mitochondrial ATP production and, indirectly, to potential oxidant generation [69]. Overall, these elements are in fully agreement 
with the other findings demonstrating altered bioenergetics profiles and enhanced mitochondrial superoxide production in RTT fibroblasts [44]. Thus, the overexpression of mitochondrial genes could mean the tendency of cells to cope with the suppressed bioenergetics, where both mitochondrial respiration and glycolysis are decreased at basal condition and, when stimulated, exhibit a reduced response [44].

The expression of transcription factors related to mitochondrial biogenesis is also affected in RTT fibroblasts isolated from patients skin biopsies, in particular with a downregulated protein expression for PGC-1 $\alpha$ (peroxisome proliferator-activated receptor gamma coactivator 1-alpha) and its downstream target gene, NRF1 (nuclear respiratory factor 1). In contrast, the mitochondrial transcription factor Tfam, whose expression is in turn primed by NRF1, is found to be up-regulated in RTT [44]. In agreement with these findings, gene and protein levels of PGC-1 $\alpha$ are significantly decreased in the skeletal muscle of symptomatic Mecp2-null mice [66].

The redox dysregulation in RTT can be also a consequence of reduced antioxidant capacities. First evidences date back to the late 80 's, when a post-mortem study showed abnormal low levels of ascorbic acid and reduced glutathione (GSH) in different brain regions of a RTT patient [70]. Formichi et al. [71] demonstrated that, compared with controls, some children with RTT had significantly lower tocopherol serum levels. Deficit in GSH metabolism has also been reported in human RTT skin fibroblasts [72], while a slight increase of GSH was noticed in erythrocytes from RTT patients [73]. In RTT mouse models, a decreased GSH/GSSG ratio was observed in the brain of Mecp2-null mice [74] and reduced GSH levels were found in skeletal muscles of symptomatic, but not pre-symptomatic, mice, suggesting that this event coincides with disease progression [66].

In a work published at the beginning of two thousand, no significant differences in the activity of glutathione peroxidase (GPx), glutathione reductase (GR) and catalase (CAT) were observed in RTT erythrocytes, whereas the activity of superoxide dismutase (SOD) was significantly reduced [75]. In a more recent study, instead, enzymatic activities of SOD and CAT did not showed significant changes in RTT erythrocytes with respect to controls [76]; while in a different cell type, i.e. dermal primary fibroblasts, a decreased activity of GPx, SOD and thioredoxin reductases (TrxR) has been reported [44]. SOD1 enzymatic activity was also reduced in hippocampal samples from Mecp2-null mice [65]. Similar, overexpression of SOD1, CAT, peroxiredoxin (PRDX1) and other antioxidant genes such as glutathione S-transferase omega 1, microsomal glutathione S-transferase 2, and microsomal glutathione Stransferase 3 was evident in PBMC from RTT patients [69]. Furthermore, the transcriptional expression levels of key genes involved in detoxification of lipid peroxidation byproducts, such as alcohol dehydrogenase 5, aldo-keto reductase family 1 member A1 and aldehyde dehydrogenase 1 family member A1 was also up-regulated, implicating a probable compensatory mechanism to cope the increased lipid peroxidation in RTT [69]. Likewise, using four independent cDNA microarray technologies, Colantuoni and colleagues identified the overexpression of transcripts for CAT and glutathione S-transferase in human RTT brain [77]. Moreover, the gene expression of metallothioneins, low weight proteins involved in several key cellular processes such as metal ions homeostasis, detoxification and scavenging of free radicals, showed in human RTT leukocytes a dysregulated pattern of expression that correlated with the phenotype severity of the disease; in particular, the mRNA level of metallothionein-1A was about 14 fold higher in RTT than in the control group [76].

\subsection{Lipid peroxidation in RTT}

Overall evidence from the previously mentioned studies indicates the existence of defective molecular processes able to cause OxS, leading to oxidative damage in RTT cells and tissues. Under redox imbalance, polyunsaturated fatty acids (PUFAs), abundant in biological membranes of cells and organelles, represent the primary target for reactive oxygen species (ROS) attack, which lead to the formation of several lipid peroxidation byproducts among others $\alpha, \beta$-unsaturated aldehydes such as 4-hydroxynonenal (4HNE), and prostaglandin-like end-products termed isoprostanes (IsoPs) [78-81]. These secondary byproducts are highly reactive, but also relatively stable, therefore they are able to diffuse from the site of production to distant tissues, where they can amplify and propagate the initial injury through sequential stages of reversible and/or irreversible oxidative modifications [82]. Based on their concentration, lipid peroxidation byproducts cause protein and DNA damage, enzymatic inactivation, alterations of membrane function, cell signaling impairment, and toxic effects on physiological processes that can lead to cell death [83-85].

A strong link between lipid peroxidation and several pathologies as neurodegenerative disorders, inflammation, cardiovascular diseases, autoimmune diseases, cancer, diabetes and aging has been revealed by elevated levels of lipid peroxidation markers [86]. Due to their features, these compounds should not be considered mere pathological biomarkers, but rather as mediators of disease $[87,88]$. Multiple studies published in last fifteen years clearly corroborate the idea of lipid peroxidation involvement in RTT, suggesting a possible role of products such as 4HNE and IsoPs in the pathogenic mechanisms of this neurodevelopmental disorder [89].

\subsection{4-hydroxynonenal in RTT}

4HNE derives from the oxidation of omega-6 PUFAs, such as arachidonic (AA), linoleic and linolenic acids [84,85]. The ability to participate in electrophilic reactions such as Michael addition as well as Schiff base formation, is responsible for most biological and pathophysiological functions of 4HNE. In a normal physiological status, low concentrations of this aldehyde are present in almost all cells and body fluids, where 4HNE plays a part, as a multifaceted mediator, in several signaling pathways and cell processes $[86,90]$. While under redox imbalance, when its levels markedly increase, 4HNE can react in an indiscriminate manner with several targeted macromolecules such as proteins, principally those containing histidine, cysteine and lysine residues, lipids, which contains an amino group, and with nucleic acids, mostly with the guanosine moiety of DNA, causing cellular dysfunction and tissue damage $[90,91]$. In particular, the interactions with proteins, defined 4HNE-protein adducts (4HNE-PA), can irreversibly impair their structure and consequently their function and appear involved in a large number of diseases including Alzheimer, Parkinson, Huntington and amyotrophic lateral sclerosis [92], Down syndrome [93], liver diseases [94], cancers [95], chronic obstructive pulmonary disease [96], and cardiovascular diseases [97,98], autoimmune diseases [99], etc.

Since RTT is a neurological disease caused by dysfunction of MeCP2 protein, mainly abundant in brain, it is possible that lipid peroxidation byproducts can play a major role also in its pathogenesis and progression, especially in the critical period of human brain development $[32,33]$. In line with the hypothesis of the lipid peroxidation involvement in neurodevelopment, recent works from our and other groups showed the presence of increased 4HNE-PA levels in plasma and erythrocytes membrane of children affected by autism $[100,101]$ as well as in brain of rats exhibiting autism-like behaviors caused by prenatal valproic acid exposure [102]. Of note autism is another neurodevelopmental disorder that shares some clinical aspects with RTT [103].

One of the first study able to demonstrate a possible involvement of lipid peroxidation in RTT dates back to 2001, when Sierra and collaborators found in RTT patients a significant increase of plasma MDA concentrations [75]. The authors speculated that high levels of this lipid peroxidation end-product reveal a peroxidative damage of bio-membranes that may contribute to progressive dementia, impaired motor function, behavioral changes, and seizures, typical features of RTT [104]. 
In the successive years, our works clearly confirmed the lipoperoxidative hypothesis of RTT, supporting the evidence, not only of an oxidative damage of bio-membranes lipids with 4HNE and IsoPs production, but also demonstrating the occurrence of a coexisting protein injury due to the formation of 4HNE-PA in several samples from RTT animal models and patients [35,36,44,72,73,105-108]. In addition, the detection of 4HNE-modified proteins in RTT samples, besides being a further parameter for the demonstration of in vivo lipid peroxidation, has provided an additional tool for discriminating what physiological processes can be altered in the disorder.

As index of a condition of systemic redox imbalance implicating lipid peroxidation events in various organs and/or tissues, high 4HNEPA levels were detected in plasma of subjects affected by typical RTT; 4HNE-PA directly correlated to both, the clinical course and to the phenotypic severity of the syndrome [36]. In the typical RTT (MECP2 mutation) the level of modified proteins by $4 \mathrm{HNE}$ varied progressively during the natural course of syndrome. No differences were observed in the stage $I^{\circ}$ in comparison to the healthy controls, while significantly higher levels of the aldehyde-modified proteins were found in children in stages $\mathrm{III}^{\circ}$ and $\mathrm{IV}^{\circ}$, although the most prominent increase occurred between the first and second stage of disease (Fig. 2) [36].

RTT is a particularly challenging condition relatively to the severity of motor and cognitive impairment, which characterizes the last stages of the disease [2]. The increase of plasma 4HNE-PA levels with the deterioration of RTT clinical picture in the stages $\mathrm{III}^{\circ}$ and $\mathrm{IV}^{\circ}$ could depend from the imbalance between the protein oxidation process and the degradation of oxidized proteins. Maintaining of the physiological equilibrium is the result of various factors: from one side, the ROS production and the antioxidant abilities, and on the other, the levels and activity of the systems for removal of oxidatively damaged proteins. As mentioned in previously paragraphs, several aspects can make RTT more susceptible to redox imbalance which, in turn, can justify for a marked acceleration in the accumulation of oxidatively damaged proteins, for example, NOX activation, mitochondrial dysfunction and impairment of antioxidant enzyme activities [44]. It is also well known a progressive accumulation of oxidatively modified proteins with age as a consequence of their increased resistance to degradation or altered cell protein quality control system [109,110]. Furthermore, proteins modified by $4 \mathrm{HNE}$ are not only resistant to proteolysis, but can also inhibit the proteasome activity, hindering the degradation of the oxidized forms of other proteins [111,112]. Of note, recent evidence from our studies clearly shown that in primary fibroblasts from RTT patients the activity of the proteasome machinery is impaired [44]. Therefore, it is possible to hypothesize that the presence of plasma 4HNE-PA accumulation in the last stages of disease can mirror what occurs in aging and several age-related diseases
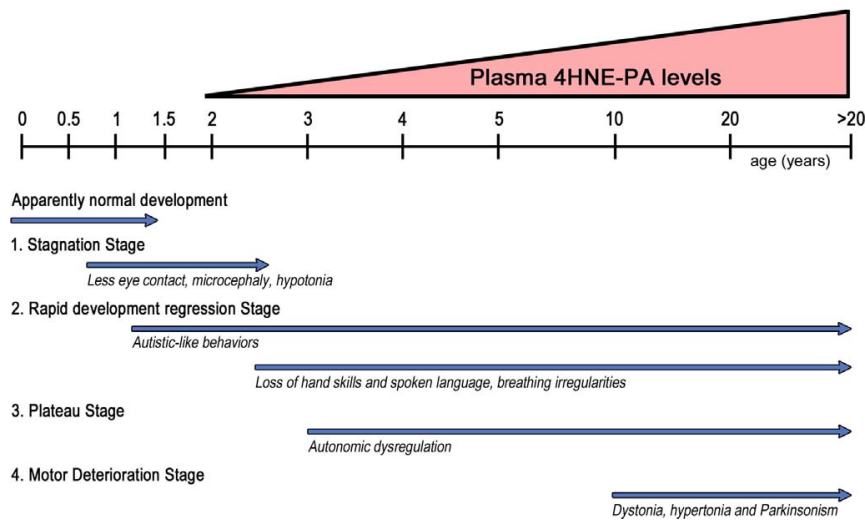

Fig. 2. Plasma 4HNE-PA levels directly correlate to the clinical course of Rett syndrome. Levels of plasma 4HNE-PA vary progressively during the natural course of syndrome. No differences are observed in the stage $\mathrm{I}^{\circ}$ in comparison to the healthy controls, while significantly higher levels of 4HNE-PA are found in children in stages $\mathrm{III}^{\circ}$ and $\mathrm{IV}^{\circ}$.
$[109,110]$.

Typical RTT was also characterized by a marked increase in levels of IsoPs deriving from the nonenzymatic oxidation of $\mathrm{AA}$, docosahexaenoic acid (DHA) and adrenic acid (AdA) during every clinical stages of the disease. As marker of AA oxidation and thus to be considered an index of generalized lipid peroxidation [113], plasma $\mathrm{F}_{2}$-IsoPs were always above the physiological range [34], showing significantly higher levels mostly in the early phases of the natural progression of classic RTT rather than in the last stages $\left(\mathrm{III}^{\circ}\right.$ and $\mathrm{IV}^{\circ}$ ) [38]. Of note, extremely high levels of $\mathrm{F}_{2}$-dihomo-isoprostanes ( $\mathrm{F}_{2}$-dihomo-IsoPs) were observed in plasma from RTT patients in the stage $I^{\circ}$ [114], which is characterized by a dramatic neurological regression [2]. These IsoPs are the prominent oxidation byproduct of AdA [113], a specific component of myelin, therefore their presence at the earliest stage of disease seems to support the concept that brain white matter damage and the clinical onset of neuroregression occur at the same time in RTT. In addition, during the RTT progression, a dramatic decrease in plasma $\mathrm{F}_{2}$-dihomoIsoPs was observed, although levels did not reached the normality range, thus strongly indicating that a damage of brain white matter must be present throughout all the natural history of the disease [114].

$\mathrm{F}_{4}$-neuroprostanes $\left(\mathrm{F}_{4}\right.$-NeuroPs), appear as another useful tool to evaluate a possible brain oxidative injury, given their origin from the free radical catalyzed peroxidation of DHA, an essential constituent of nervous tissue, highly enriched in neurons [113]. In typical RTT, plasma $\mathrm{F}_{4}$-NeuroPs levels were significantly higher than in controls during the natural history of the disease, without statistically significant differences between individual stages, that may signify that oxidative brain damage occurs during all the stages of RTT progression [37].

Significant differences are observed in plasma 4HNE-PA levels between groups of patients with different clinical presentation of the syndrome, suggesting that the multiplicity of genotypic and phenotypic aspects of RTT are reflected in the extent of OxS levels. Among the MECP2-related variants, PSV is a mild form characterized by a relatively benign course and, although those patients share a number of symptoms common to classic RTT, these girls show better manual and language abilities [11]. In accordance to their clinical phenotype, plasma 4HNE-PA levels appeared slightly lower in PSV compared to classic phenotype [36]. In line with this trend, an exome sequencing study on two pairs of sisters with identical MECP2 mutation, but different phenotype (typical $v$ PSV), revealed the occurrence of lower redox imbalance in the PSV form. Indeed, each PSV sister was more similar to control for the levels of various lipid peroxidation biomarkers levels such as $\mathrm{F}_{2}$-IsoPs (which denote a systemic oxidative lipid damage), $\mathrm{F}_{4}$-NeuroPs and $\mathrm{F}_{2}$-dihomo-IsoPs (that instead are indicators of specific grey and white matter injury, respectively) [39]. In accordance with this evidence, variants predicted to impair protein function in several genes involved in OxS were also identified in classical RTT subjects, including GFPT2 (glutamine: fructose-6-phosphate amidotransferase), which exerts a protective effect against hydrogen peroxide toxicity in neuronal cells; AOX1 (aldehyde oxidase), that catalyzes the formation of superoxide and ASMT (acetylserotonin methyltransferase-like), involved in the synthesis of melatonin. On the other hand, a subgroup of variants related to interleukin and chemokine receptors and thus to the modulation of immune system were exclusive to the PSV patients, which in contrast exhibited only a few variants in genes related to OxS, among which ASL (argininosuccinate lyase), CPOX (coproporphyrinogen oxidase), and GLDC (glycine decarboxylase). This study of familial cases reveals how the expression of a discordant phenotype in RTT patients is likely the result of a combination of mutations in MECP2, $\mathrm{X}$ inactivation status, and disrupting variants in other genes [39].

In general, most patients with the CDKL5 disorder shows impaired functional abilities, and more severe clinical characteristics that in $M E C P 2$ subjects. In line with this statement, a trend in rising plasma 4HNE-PA levels was appreciable in CDKL5 patients compared to classic RTT. On the other hand, no differences were detected in FOXG1 4HNE- 
PA plasma levels [36]. Although, at present, the possible cause for the observed difference in FOXG1 behavior is not understood, it should be mentioned that, while a possible OxS involvement in the CDKL5 disorder has been recurrently recognized $[107,115]$, at present no study has documented such evidence in FOXG1. A part of these distinct 4HNE-PA phenotypes could be partially ascribed to the different chromosome location and function of the FOXG1. Indeed, both MECP2 and CDKL5 genes are located on the X chromosome, while FOXG1 on chromosome 14 [13]. In addition, CDKL5 protein belongs to the same molecular pathway of MeCP2, given that it is a kinase able to phosphorylate itself and to mediate MeCP2 phosphorylation [116]; CDKL5 has been also reported to be a MeCP2-repressed target gene [117]. Thus, these close biochemical relationships could partially justify the overlapping aspect in the 4HNE-PA levels between MECP2 and CDKL5 and their difference respect to FOXG1 disorder.

The 4HNE-PA plasma levels findings in RTT partly overlap with those for IsoPs. In general, $\mathrm{F}_{2}$-IsoPs plasma levels were higher in CDKL5 patients than in PSV and FOXG1, but similar to classic RTT subjects [38]. Plasma levels of $\mathrm{F}_{4}$-NeuroPs in PSV and CDKL5 patients were intermediate between the values of typical RTT and controls [37]. No statistical differences were observed in plasma levels of $\mathrm{F}_{2}$-dihomoIsoPs in PSV patients compared to healthy control, while CDKL5 patients showed plasma levels of $\mathrm{F}_{2}$-dihomo-IsoPs comparable to those detected in the late stages of typical RTT (clinical stages $\mathrm{II}^{\circ}$ to $\mathrm{IV}^{\circ}$ of the disease) [114]. Taken together, these findings denote that lipid peroxidation is consistently increased in classic MECP2 and CDKL5 disorders, whereas it appears to be less evident in the PSV and FOXG1 patients.

Interestingly, in patients with typical RTT $\mathrm{F}_{2}$-IsoPs as well as $\mathrm{F}_{4^{-}}$ NeuroPs levels were correlated to mutation type and clinical severity of the syndrome. In general, MECP2 mutations located in critical regions that carry higher phenotype severity usually showed a more pronounced OxS imbalance; this particular genotype-phenotype correlation suggests that the degree of MeCP2 protein dysfunction can be directly linked to the OxS-mediated systemic and neuronal damage $[38,114]$.

Previous reports demonstrated the evidence of systemic and, potentially, brain lipoperoxidative damage in RTT patients, as indicated by increased plasma levels of 4HNE-PA and IsoPs [36-38,114]. Beyond to generate a number of reactive byproducts, lipid peroxidation causes serious damages to cell membranes, changing not only membrane fluidity but also reducing the activities of membrane-bound enzymes, ion channels, and receptors. In addition, the same lipid peroxidation end-products can directly attack membrane proteins and induce lipidprotein and protein-protein crosslinking, all of which contribute further to propagate the membrane damage.

One of the first cells to be affected by systemic lipid peroxidation is the "red blood cell" (RBC). Indeed, erythrocytes, the most abundant cells in the human organism, are directly exposed to the biochemical milieu of plasma. In addition, the exposure to high concentrations of oxygen and haemoglobin, the absence of organelles including nucleus and mitochondria, incapacity to synthesize new proteins and detoxifying enzymes, make RBC extremely sensitive to oxidative damage with erythrocyte membrane particularly prone to undergo lipid peroxidation under OxS condition [118,120,1119].

This notion is in line with recent findings which showed a significant increase of MDA in RTT patients erythrocytes [76]. Furthermore, the occurrence of lipid peroxidation events was also confirmed from our group through the detection of increased levels of esterified $\mathrm{F}_{2}$-IsoPs and 4HNE-PA in erythrocyte membranes from RTT patients [73]. Interestingly, the membrane oxidative damage resulted strictly associated to higher percentage of abnormally shaped erythrocytes, mainly leptocytes. Of note, antioxidant substances such as $\omega-3$ PUFA, by inducing a decrease in these membrane lipid peroxidation byproducts, were partially able to rescue the altered RBC shape by increasing the percentage of the atypical forms reversible to discocytes, i.e. stomatocytes, confirming the concept that oxidative alteration of membrane lipids can have profound effects on RBC morphology and other cell properties [73].

Lipid peroxidation process appears to be involved in the abnormal RBC shape in RTT also through the harmful modulation of their cytoskeleton. In fact, a proteomic study revealed $\beta$-actin deficit consequent to oxidative post-translational modifications (PTMs) via 4HNE in the inner interface of the RTT erythrocyte membranes [96]. Since it is well known that $\beta$-actin is an essential protein in the RBC cytoskeleton, its expression changes as a consequence of oxidative damage could contribute to the RBC abnormal shape, previously mentioned in RTT. In addition, oxidative PTMs by 4HNE were also noticed in other erythrocyte proteins (i.e. spectrin $\alpha$ and $\beta$ chains, ankyrin, band 3 , protein 4.1 , adducin, protein $4.2,55 \mathrm{kDa}$ protein, tropomodulin, aldolase and glyceraldehyde-3-phosphate dehydrogenase), many of which are related to an increased susceptibility of erythrocytes to mechanical stress [121]. As previously reported for the $\mathrm{RBC}$ shape and oxidative membrane damage [73], the disruption of the RTT erythrocyte cytoskeletal-membrane protein network was partially rescued by $\omega-3$ PUFA supplementation [121].

A further confirm of the role for 4HNE-PA in cell redox dysregulation is emerged in studies conducted on primary fibroblasts isolated from RTT patient skin biopsies [44,72,105,107,108]. Besides supporting the presence of high 4HNE-PA levels in RTT fibroblasts, the first of the these studies showed also the loss of the HDL receptor, "scavenger receptor B1" (SRB1), as a consequence of PTMs related to the covalent binding with 4HNE and to the subsequent ubiquitination, which leaded to receptor degradation via the proteasome system [105]. Since SRB1 mediates the selective uptake of cholesteryl esters from HDL as well as LDL in the liver and other tissues [122], its dysfunction could explain the coexistence of an altered lipid profile characterized by high levels of HDL and LDL in the plasma of RTT patients, which cannot be associated to an unhealthy diet [105]. The alteration in plasma lipid profile linked to the 4HNE-SRB1 adducts formation in RTT is a classic example of the 4HNE ability to affect cell signaling pathways and metabolic processes, leading to the onset of pathological conditions. Moreover, this finding is in accordance with recent papers, which revealed the cholesterol homeostasis perturbation in RTT with changes in the activity/expression of genes and proteins involved in the cellular uptake, synthesis and feedback regulation of circulating cholesterol [123-128]. In light of the above, it appears obvious that lipid metabolism assumes the role of a strong potential therapeutic target for treating specific clinical features of this disorder.

Interestingly, the altered serum lipid profile associated with an oxidative-mediated loss of SRB1, due to the 4HNE adduction and ubiquitination, previously noticed in MECP2 patients is also present in CDKL5, as demonstrated in a study on primary skin fibroblasts from affected patients [107]. This condition parallels whit an aberrant activation of Nrf2, a redox-sensitive transcription factor able to regulate the expression of many "antioxidant" genes and other cytoprotective phase II detoxifying enzymes [129]. The decreased nuclear Nrf2 translocation in CDKL5 cells, once challenged with oxidative insults, indicates the inability of these cells to induce a proper defensive response which can partly justify the observed redox imbalance and the increased SRB1/4HNE and SRB1/nitrotyrosine adducts levels. Finally, this work also suggests that the altered lipid serum profile can represent a new possible common denominator between two different RTT variants, MECP2 and CDKL5, which already share, not only some clinical features, but also other cellular and molecular aspects [107].

In line with the previous report on MECP2-related disorder, high levels of 4HNE-PA are detected in another study still in primary RTT fibroblasts, indicating that a systemic OxS status could originate from dysfunctional tissue/cell systems and/or potentially damage them [72]. Increased lipid oxidative damage was evidenced by increased levels of $\mathrm{F}_{2}$-IsoPs, $\mathrm{F}_{4}$-NeuroPs and 4HNE-PA, which can be considered as a long- 
term consequence of enhanced lipid peroxidation. Redox imbalance seems also to contribute to changes in some physiological aspects of RTT cells, such as the morphology and collagen distribution. Indeed, RTT fibroblasts show a reduced degree of colocalization of type III and type I collagen, with low levels of type I collagen, a typical feature of skin aging. Transmission electron microscopy (TEM) analysis was able to detect some ultrastructural abnormalities in RTT fibroblasts, among which a marked dilation of the rough endoplasmic reticulum cisternae, along with evidence of cytoplasmic multilamellar bodies [72]. On the other hand, the presence of vesicles, multilamellar structures, and multivesicular bodies are also observed in the cytoplasm of PBMC isolated from classic RTT patients [56]. This morphological aspect has to be considered of particular concern, as it may suggest the abnormal occurrence of autophagy phenomena. Evidence of "mammalian target of rapamycin" (mTOR) pathway dysfunction in RTT has been reported [130]; mTOR is a critical regulator of a diverse array of cellular processes, such as cell growth, proliferation and also autophagy, with activated mTOR (Akt and MAPK signaling) suppressing autophagic process. In contrast, mTOR signaling pathway and protein synthesis were down-regulated in RTT mouse models [131-133], suggesting the possibility of hyperactivated autophagy in RTT, which however needs to be investigated in more detail.

Further supports on the role of lipid peroxidation in RTT pathogenesis come from the work of Cervellati and colleagues [44], who recently reported a significant increase of 4HNE-PA associated with high intracellular levels of hydrogen peroxide in fibroblasts isolated from MECP2 patients. This finding is correlated with the mitochondrial dysfunction, i.e. increased mitochondrial oxidant production and altered mitochondrial biogenesis, and constitutive activation of NOX. In addition, the activity of several enzymes involved in protecting the cell from OxS, such as SOD, GPx and TrxR were decreased respect to control. It is possible to deduce that superoxide, produced by mitochondria and NOX, rapidly dismutate to form hydrogen peroxide and molecular oxygen. In presence of a reduced antioxidant enzymes activity, hydrogen peroxide can trigger lipid peroxidation through the iron-catalyzed Fenton reaction, as confirmed by the elevated 4HNE-PA found in the RTT fibroblasts. In addition, these data concurred with a constitutive activation of $\mathrm{Nrf} 2$ and an enhanced gene expression of Heme oxygenase-1 (HO-1) and $\mathrm{NAD}(\mathrm{P}) \mathrm{H}$ dehydrogenase quinone 1 (NQO-1) [134]. Of note, when RTT fibroblasts were stimulated via exogenous oxidants, they did not responded as the control cells, showing a less pronounced nuclear translocation of Nrf2 [134]. Besides these alterations, it is possible to speculate that also the decreased enzymatic activities of proteasome (i.e. caspase-, chymotrypsin- and trypsin-like activities), revealed in RTT cells, can contribute to the pool of 4HNE-modified proteins [44]. Furthermore, the impaired protein clearance through the ubiquitin-proteasome system dysfunction seems correlate with a recent microarray analysis on RTT PBMC, where it was noticed an up-regulation of several genes related to protein degradation and ubiquitination, which it should be interpreted as a possible transcriptional compensation activated by a positive feedback loop [69].

Accumulation of oxidized proteins can cause abnormal physiological cell functions and it is well known to play a key role in the pathophysiology of disorders associated with OxS, particularly in neuropathologies. Probably, 4HNE-mediated PTMs could be critically involved also in pathogenesis and progression of MECP2- and CDKL5related disorders, as demonstrated by SRB1 loss due to 4HNE adducts formation and subsequent ubiquitination, which then lead to its degradation via the proteasomal machinery. This sequence of events, triggered by $4 \mathrm{HNE}$ adduction, might be the culprit of several clinical feature of these syndromes, not only the altered serum lipid profile $[105,107,127]$, but also the frequent respiratory and urinary infections [135] or the lower serum vitamin E levels [71], since it is also wellknown the SRB1 function in pathogens recognition and $\alpha$-tocopherol tissue uptake [122]. Similarly, the $\beta$-actin deficit in RTT erythrocytes represents another example of 4HNE-mediated redox regulation of cytoskeletal proteins in RTT [106,121], which can have detrimental consequences on various cellular aspects, such as morphology, vesicle trafficking, intracellular organization, cell contraction and motility.

Therefore, the identification of other 4HNE-modified proteins may allow to better understand the molecular pathways affected in RTT by an exacerbated lipid peroxidation. As a "logical" prosecution of previous investigations in which the presence of OxS has been analyzed and documented, the work of Pecorelli and collaborates [108] shifts the attention from the causative mechanisms [44] to the biological consequences of $\mathrm{OxS}$, focusing on the identification of the proteins targeted by oxidative modifications by either 4HNE and, in addition, peroxynitrite in RTT cells. Using a redox proteomic approach, fifteen different proteins were identified as target for 4HNE adduction in primary RTT fibroblasts [108]. Moreover, another common and abundant type of oxidative modification to proteins is the 3-nitrotyrosine (3NT) formation, a marker derived from the biochemical interaction of nitric oxide (NO) or NO-derived secondary products with ROS; in this same study seven proteins show a significant increase in 3NT modifications. The oxidatively modified proteins are involved in different cell processes such as cytoskeleton structure and organization, protein folding and energy metabolism, all biological functions which seem to be perturbed in RTT patients, as previously mentioned (Fig. 3) [108].

Most neurodegenerative diseases as well as several syndromes associated with mental retardation are characterized by defects in the cytoskeletal architecture that, in neurons, is crucial for shape, trafficking and dendritic developmental processes [136]. Furthermore, it has been recently demonstrated the presence of several cytoskeletal proteins modified by $4 \mathrm{HNE}$ in brain of subjects affected by pathologies such as Down syndrome and Alzheimer [137-139]. Structural and functional alterations in the microfilaments, microtubules and neurofilaments, potentially leading to abnormal dendritic spine morphology with reduced dendritic arborization, appear to be central in RTT pathogenesis, being also causally linked to MeCP2 deficiency $[140,141]$. In particular, recent studies reported the alteration of microtubule dynamics and vesicular transport in mouse and human MeCP2-deficient astrocytes and fibroblasts [142-144]; moreover, $\mathrm{MeCP} 2$ localizes in the centrosomes of both dividing and non-proliferating cells, and MeCP2 deficit causes several alterations linked to centrosome dysfunction, such as a prolonged mitosis, abnormal cell cycle and/or mitotic spindle geometry, and defects in microtubule nucleation [145].

Through the redox proteomics analysis, our group was able to identify increased levels of 4HNE and/or 3NT modifications in RTT proteins involved in cytoskeletal network such as the major constituent of microtubules $\beta$-tubulin (TBB1) and $\beta$-actin (ACTB). Furthermore, two proteins implicated in the stabilization of actins filaments in nonmuscle cells, i.e. the tropomyosin isoforms TPM1 and TPM2, have also reported to present redox PTMs [108]. In particular, the data regarding to $\beta$-actin PTMs fully agrees with the previous report on the increased 4HNE adducts with $\beta$-actin present in the RTT erythrocytes [106]. Finally, cytoskeleton impairment might also derive by the damaged functions of other two oxidatively modified proteins, such as the

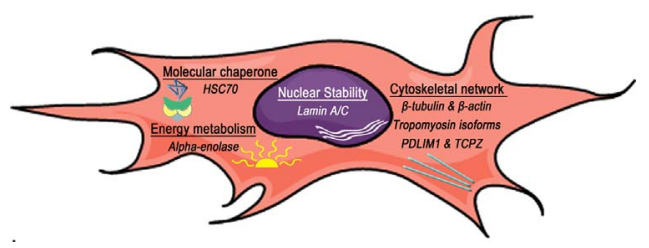

Fig. 3. Specific protein targets for 4-HNE adduction in primary RTT fibroblasts. The oxidatively modified proteins by $4 \mathrm{HNE}$ are involved in cell processes such as cytoskeleton structure and organization, protein folding and energy metabolism, all biological functions that are altered in RTT patients. 
multirole adapter PDLIM1 (PDZ and LIM domain protein 1) and TCPZ (T-complex protein 1 subunit zeta), a molecular chaperone assisting the folding of both actin and tubulin [108]. The most significant finding of this proteomics study highlights that, if similar oxidative PTMs via 4HNE and/or NT occur also in cytoskeleton of neurons in the brain, they could contribute to the characteristic RTT defects of spine morphology and dendritic arborization.

In accordance with recent evidences of a severe impairment of proteasome activity and upregulation of protein ubiquitination $[44,105]$, also the downstream processes, such as recognition and recruitment of proteins with abnormal conformation appeared to be compromised in RTT fibroblasts. Indeed, two members of the heat shock proteins family, HSC70 and GRP78, showed 4HNE or NT modifications, respectively [108]. While GRP78, expressed in response to endoplasmatic reticulum (ER) stress, is primarily involved in the targeting and trafficking of misfolded proteins for ER-associated degradation, HSC70 is a constitutively expressed cytoplasmic chaperone that plays a large variety of cellular functions under non-stress conditions. Major cellular functions of HSC70 are its involvement in protein folding, protein degradation, notably its implication in the ubiquitin-proteasome pathway, and in addition in the translocation of proteins into organelles such as ER and mitochondria. Because its involvement as key component of chaperone-mediated autophagy [146], 4HNE-mediated modifications of HSC70 could also contribute to autophagy impairment in RTT.

Several disorders affecting energy metabolism have been documented in RTT, including defects in mitochondrial respiration and glycolysis [44]; in particular, the last aspect agrees with the evidence of increased 4HNE-mediated PTMs in $\alpha$-enolase, a multifunctional glycolytic enzyme involved in cellular stress [108].

\subsection{Lipid peroxidation and RTT mouse models}

In the past years, several RTT animal models have been generated to recapitulating many symptoms of the human phenotype, allowing also the investigation of the underlying pathogenic mechanisms [147]. To prove that the occurrence of OxS is a typical hallmark of RTT, recent studies have focused attention on the evaluation of the redox status and its possible modulation by antioxidants in some experimental models of syndrome [35,65-67,148,149].

An impaired redox balance linked to mitochondrial dysfunction has been revealed in brain and muscle samples from several mouse models of RTT in different studies, which reported a more oxidized baseline condition by the quantification of cytosolic redox balance with the genetically-encoded optical probe roGFP1 [65], a decreased GSH level [66] and a marked increase in the rate of hydrogen peroxide generation in the brain of RTT mice [67].

Evidence for systemic and brain oxidative damage emerged in a study on five different RTT mouse models (Mecp2-null pre-symptomatic, symptomatic, and rescued; Mecp $2^{-308}$ mutated pre-symptomatic and symptomatic) [35]. First, the increased concentrations of plasma $\mathrm{F}_{2}$-IsoPs in symptomatic Mecp2 $2^{-/ y}$ and Mecp2 $2^{308 / y}$ mutated mice has clearly indicated the occurrence of systemic lipid peroxidation phenomena during the symptomatic phase of the disorder. Then, the detection of elevated levels of lipid peroxidation markers such as $\mathrm{F}_{2}$ IsoPs, $\mathrm{F}_{4}$-NeuroPs and 4HNE-PA in whole brain tissues from the Mecp2 mutant experimental models has also confirmed the oxidative damage in the main target organ of RTT, with neurons, but not astroglia, as the most vulnerable cell type to lipid peroxidation. These findings confirmed the relationship between the symptomatic phase of the syndrome and the fatty acid peroxidation, leading to lipid and protein damage, as previously mentioned [36-38,114]. When analyzed in brain of pre-symptomatic animals, significant increased levels of $\mathrm{F}_{2}$-IsoPs and $\mathrm{F}_{4}$-NeuroPs were also observed, indicating that the oxidative brain damage is present prior to the onset of the typical manifestations of the disorder and is a previously unrecognized hallmark feature in RTT animals [35]. Additionally, the evidence for lipoperoxidative phenomena at different stages of this disorder underscores the critical role that this process could have in both RTT pathogenesis and progression.

As a further proof of a potential cause-effect relationship between Mecp2 protein deficiency and oxidative brain damage is the fact that the redox homeostasis was reestablished following the brain-specific Mecp2 gene reactivation; indeed, the rescued Mecp2 stop/y NestinCre animals showed levels of IsoPs comparable to those of age-matched wild-type (WT) mice [35], thus indicating the possibility that OxS imbalance in RTT can be a reversible phenomenon, which is corrected by the reintroduction of a functional Mecp2 protein.

A more recent preclinical study, which aimed to define the merit of systemic administration of the vitamin E-derivative Trolox in Mecp $2^{-/ y}$ male mice, has failed in demonstrating the presence of lipid peroxidation markers in the isolated brain tissue [149], although a previous report from the same research group was able to prove an increased oxidative burden and mitochondrial dysfunction in hippocampal tissue from the same RTT murine model $[65,148]$. However, it also should be noted here that the same authors have explicitly indicated some possible limitations in the experimental methods, since the sensitivity range of the used assays may not be ideal to detect reliably changes in protein and lipid oxidation [149].

In particular, no differences were observed in MDA levels between neocortical samples from WT and $\mathrm{Mecp} 2^{-/ y}$ mice, while protein carbonyls, a marker of protein oxidation, were increased in RTT animals. Of note, the degree of oxidative damage in brain tissue of Mecp $2^{-/ y}$ mice was ameliorated at least partly by Trolox treatment, as demonstrated by the tendency to decrease lipid peroxidation and protein carbonyls content in the neocortex of treated animals as compared to the corresponding untreated Mecp2-null mice [149]. Along this line, in vitro acute treatment of hippocampal slices with Trolox has ameliorated some characteristic neurological aspects of RTT, in particular has dampened the neuronal hyperexcitability, reinstated the synaptic plasticity, improved the hypoxia tolerance and also rescued cellular redox balance in male Mecp2-deficient mice [148].

In view of the fact that several studies in animal models have showed as the restoration of Mecp2 in symptomatic mice markedly reverses the RTT phenotype, revealing that the syndrome does not result in degeneration of neurons or irreversible developmental impairment of neuronal networks, the previous observations on RTT animals models, providing clear evidence that Mecp2 protein deficiency is associated with a brain redox abnormality, indicate that pharmacological treatments of these symptoms with compounds similar to the freeradical scavenger Trolox could be a promising and valid co-adjuvant therapeutic approach for RTT, as already proven for supplementation with $\omega$-3 PUFAs, that has successfully reduced the levels of several OxS biomarkers in the blood of RTT patients and ameliorated some of the typical RTT symptoms [31].

\subsection{OxInflammation in RTT}

A further role for lipid peroxidation end-products in RTT could arise by their involvement in immune dysfunction, an emergent hallmark of RTT pathophysiology $[28,33]$. Indeed, it has been shown that aldehydic-protein adducts are both potential targets or inductors of the cellular and humoral immune responses [150]. In particular, when the rate of $4 \mathrm{HNE}$ protein adduction overcomes the proteasome peptidase activity, a condition further amplified by a direct 4HNE-mediated inhibition of its proteolytic subunits, the accumulation of 4HNEmodified proteins occurs into the cells. In addition, abnormal interactions between these modified proteins that result in intracellular and extracellular deposition of self-aggregating misfolded proteins. Growing evidence demonstrates that such oxidative PTMs result in the generation of neo-epitopes that, recognized by different immune receptors, are capable of eliciting both innate and adaptive immune responses [150].

Previous studies clearly support the idea of an impaired clearance of 


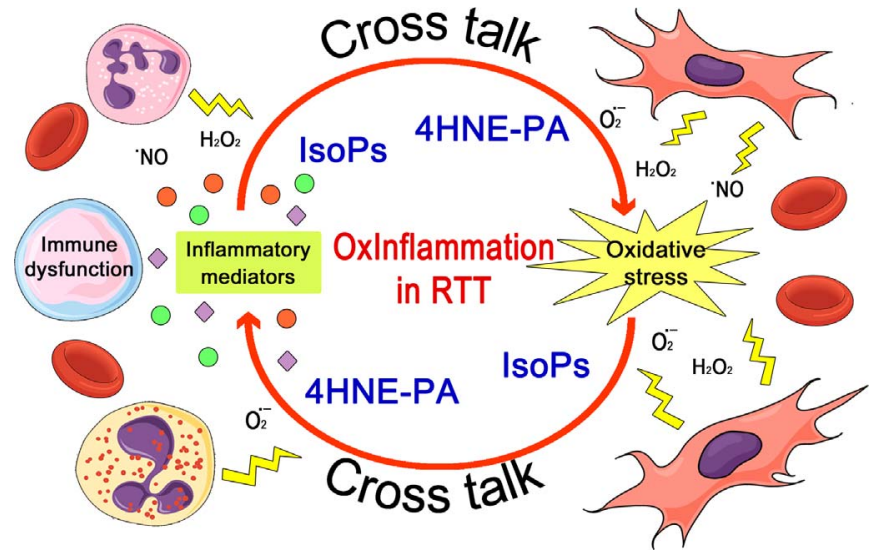

Fig. 4. OxInflammation in Rett syndrome. A steady redox imbalance associated with a subclinical and chronic inflammatory state, in a kind of harmful vicious circle, predisposes RTT patients to a condition designated as "OxInflammation", able to explain many typical clinical features of the disease.

misfolded and oxidatively modified proteins in RTT cells, mainly due to an impairment of the ubiquitin/proteasome system and probably autophagy $[44,56,108,130]$. Therefore, the 4HNE-modified proteins could act as neo-antigens also in RTT, being potentially able to initiate and drive an antibody generated immune response, mediated by $\mathrm{T}$ and/ or B lymphocytes and characterized by release of inflammatory mediators, thus contributing to disease progression and severity. Consistent with this possible scenario, a wealth of evidence from our and other laboratories suggests that a "short-circuit" of redox pathways and a condition of systemic subclinical inflammation can be critical players of a detrimental vicious circle, defined as "OxInflammation", able to affect the pathogenesis and clinical course of RTT (Fig. 4) [33]. Multiple elements support the implication of subclinical inflammation in RTT including high levels of inflammatory markers and deregulation of acute phase response (APR) proteins [151,152], an unbalanced cytokines profile $[56,115,152]$, the abnormal morphology of peripheral blood mononuclear cells (PBMCs) [56] and the impaired phagocytic activity of microglia [153].

In line with the hypothesis that 4HNE-PA may act as neoautoantigens in initiating an immune response, an autoimmune component in RTT has been also reported with an increased levels of brain-directed autoantibodies, mainly autoantibodies to nerve growth factor [154], and folate receptor autoantibodies [155].

Together, these data provide evidence for the existence of a possible association between lipid peroxidation end-products and immune system dysfunction in RTT; however, further studies are needed to establish a clear link between the formation of HNE-modified proteins and autoimmunity in RTT.

In conclusion, the present review intends to highlights the importance of peroxidation byproducts such as $4 \mathrm{HNE}$ as not just a marker of altered redox balance but as a key signaling molecule and a possible therapeutic target in a pathology, Rett Syndrome, that at today is still orphan of therapies.

\section{References}

[1] A.K. Percy, Rett syndrome, Curr. Status New Vistas Neurol. Clin. 20 (2002) 1125-1141.

[2] B. Hagberg, Clinical manifestations and stages of Rett syndrome, Ment. Retard Dev. Disabil. Res. Rev. 8 (2) (2002) 61-65.

[3] R.E. Amir, I.B. Van den Veyver, M. Wan, C.Q. Tran, U. Francke, H.Y. Zoghbi, Rett syndrome is caused by mutations in X-linked MECP2, encoding methyl-CpGbinding protein 2, Nat. Genet 23 (2) (1999) 185-188.

[4] R. Trappe, F. Laccone, J. Cobilanschi, M. Meins, P. Huppke, F. Hanefeld, W. Engel, MECP2 mutations in sporadic cases of Rett syndrome are almost exclusively of paternal origin, Am. J. Hum. Genet. 68 (5) (2001) 1093-1101.

[5] R.E. Amir, H.Y. Zoghbi, Rett syndrome: methyl-cpg-binding protein 2 mutations and phenotype-genotype correlations, Am. J. Med. Genet. 97 (2) (2000) 147-152.
[6] M. Chahrour, H.Y. Zoghbi, The story of Rett syndrome: from clinic to neurobiology, Neuron 56 (3) (2007) 422-437.

[7] P. Watson, G. Black, S. Ramsden, M. Barrow, M. Super, B. Kerr, J. Clayton-Smith, Angelman syndrome phenotype associated with mutations in MECP2, a gene encoding a methyl CpG binding protein, J. Med. Genet. 38 (4) (2001) 224-228.

[8] D. Cohen, G. Lazar, P. Couvert, V. Desportes, D. Lippe, P. Mazet, D. Héron, MECP2 mutation in a boy with language disorder and schizophrenia, Am. J. Psychiatry 159 (1) (2002) 148-149.

[9] S. Hammer, N. Dorrani, J. Dragich, S. Kudo, C. Schanen, The phenotypic consequences of MECP2 mutations extend beyond Rett syndrome, Ment. Retard. Dev. Disabil. Res. Rev. 8 (2) (2002) 94-98.

[10] J.L. Neul, W.E. Kaufmann, D.G. Glaze, J. Christodoulou, A.J. Clarke, N. BahiBuisson, H. Leonard, M.E. Bailey, N.C. Schanen, M. Zappella, A. Renieri, P. Huppke, A.K. Percy, RettSearch Consortium, Rett syndrome: revised diagnostic criteria and nomenclature, Ann. Neurol. 68 (6) (2010) 944-950.

[11] M. Zappella, The Rett girls with preserved speech, Brain Dev. 14 (2) (1992) 98-101.

[12] E. Scala, F. Ariani, F. Mari, R. Caselli, C. Pescucci, I. Longo, I. Meloni, D. Giachino, M. Bruttini, G. Hayek, M. Zappella, A. Renieri, CDKL5/STK9 is mutated in Rett syndrome variant with infantile spasms, J. Med. Genet. 42 (2) (2005) 103-107.

[13] F. Ariani, G. Hayek, D. Rondinella, R. Artuso, M.A. Mencarelli, A. Spanhol-Rosseto, M. Pollazzon, S. Buoni, O. Spiga, S. Ricciardi, I. Meloni, I. Longo, F. Mari, V. Broccoli, M. Zappella, A. Renieri, FOXG1 is responsible for the congenital variant of Rett syndrome, Am. J. Hum. Genet. 83 (1) (2008) 89-93.

[14] J.L. Neul, The relationship of Rett syndrome and MECP2 disorders to autism, Dialogues Clin. Neurosci. 14 (3) (2012) 253-262.

[15] P.L. Jones, G.J. Veenstra, P.A. Wade, D. Vermaak, S.U. Kass, N. Landsberger, J. Strouboulis, A.P. Wolffe, Methylated DNA and MeCP2 recruit histone deacetylase to repress transcription, Nat. Genet. 19 (2) (1998) 187-191.

[16] M. Chahrour, S.Y. Jung, C. Shaw, X. Zhou, S.T. Wong, J. Qin, H.Y. Zoghbi, MeCP2, a key contributor to neurological disease, activates and represses transcription, Science 320 (5880) (2008) 1224-1229.

[17] J.M. LaSalle, D.H. Yasui, Evolving role of MeCP2 in Rett syndrome and autism, Epigenomics 1 (1) (2009) 119-130.

[18] F. Ehrhart, S.L. Coort, E. Cirillo, E. Smeets, C.T. Evelo, L.M. Curfs, Rett syndrome biological pathways leading from MECP2 to disorder phenotypes, Orphanet J. Rare Dis. 11 (1) (2016) 158.

[19] U. Francke, Mechanisms of disease: neurogenetics of MeCP2 deficiency, Nat. Clin. Pr. Neurol. 2 (4) (2006) 212-221.

[20] P.J. Skene, R.S. Illingworth, S. Webb, A.R. Kerr, K.D. James, D.J. Turner, R. Andrews, A.P. Bird, Neuronal MeCP2 is expressed at near histone-octamer levels and globally alters the chromatin state, Mol. Cell 37 (4) (2010) 457-468.

[21] J. Guy, H. Cheval, J. Selfridge, A. Bird, The role of MeCP2 in the brain, Annu. Rev. Cell Dev. Biol. 27 (2011) 631-652.

[22] F. Du, M.V. Nguyen, A. Karten, C.A. Felice, G. Mandel, N. Ballas, Acute and crucial requirement for $\mathrm{MeCP} 2$ function upon transition from early to late adult stages of brain maturation, Hum. Mol. Genet. 25 (9) (2016) 1690-1702.

[23] N. Ballas, D.T. Lioy, C. Grunseich, G. Mandel, Non-cell autonomous influence of MeCP2-deficient glia on neuronal dendritic morphology, Nat. Neurosci. 12 (3) (2009) 311-317.

[24] I. Maezawa, S. Swanberg, D. Harvey, J.M. LaSalle, L.W. Jin, Rett syndrome astrocytes are abnormal and spread MeCP2 deficiency through gap junctions, J. Neurosci. 29 (16) (2009) 5051-5061.

[25] N.C. Derecki, J.C. Cronk, Z. Lu, E. Xu, S.B. Abbott, P.G. Guyenet, J. Kipnis, Wildtype microglia arrest pathology in a mouse model of Rett syndrome, Nature 484 (7392) (2012) 105-109.

[26] M.V. Nguyen, C.A. Felice, F. Du, M.V. Covey, J.K. Robinson, G. Mandel, N. Ballas, Oligodendrocyte lineage cells contribute unique features to Rett syndrome neuropathology, J. Neurosci. 33 (48) (2013) 18764-18774.

[27] D.H. Yasui, H. Xu, K.W. Dunaway, J.M. Lasalle, L.W. Jin, I. Maezawa, MeCP2 modulates gene expression pathways in astrocytes, Mol. Autism 4 (1) (2013) 3.

[28] J.C. Cronk, N.C. Derecki, V. Litvak, J. Kipnis, Unexpected cellular players in Rett syndrome pathology, Neurobiol. Dis. 92 (Pt A) (2016) 64-71. http://dx.doi.org/ 10.1016/j.nbd.2015.05.005.

[29] D.T. Lioy, S.K. Garg, C.E. Monaghan, J. Raber, K.D. Foust, B.K. Kaspar, P.G. Hirrlinger, F. Kirchhoff, J.M. Bissonnette, N. Ballas, G. Mandel, A role for glia in the progression of Rett's syndrome, Nature 475 (7357) (2011) 497-500.

[30] J.C. Cronk, N.C. Derecki, E. Ji, Y. Xu, A.E. Lampano, I. Smirnov, W. Baker, G.T. Norris, I. Marin, N. Coddington, Y. Wolf, S.D. Turner, A. Aderem, A.L. Klibanov, T.H. Harris, S. Jung, V. Litvak, J. Kipnis, Methyl-CpG binding protein 2 regulates microglia and macrophage gene expression in response to inflammatory stimuli, Immunity 42 (4) (2015) 679-691.

[31] C. De Felice, C. Signorini, S. Leoncini, A. Pecorelli, T. Durand, G. Valacchi, L. Ciccoli, J. Hayek, The role of oxidative stress in Rett syndrome: an overview, Ann. NY Acad. Sci. 1259 (2012) 121-135.

[32] S. Filosa, A. Pecorelli, M. D'Espositoc, G. Valacchi, J. Hajek, Exploring the possible link between MeCP2 and oxidative stress in Rett syndrome, Free Radic. Biol. Med. 88 (2015) 81-90.

[33] A. Pecorelli, C. Cervellati, J. Hayek, G. Valacchi, OxInflammation in Rett syndrome, Int. J. Biochem. Cell Biol. (2016).

[34] C. De Felice, L. Ciccoli, S. Leoncini, C. Signorini, M. Rossi, L. Vannuccini, G. Guazzi, G. Latini, M. Comporti, G. Valacchi, J. Hayek, Systemic oxidative stress in classic Rett syndrome, Free Radic. Biol. Med. 47 (4) (2009) 440-448.

[35] C. De Felice, F. Della Ragione, C. Signorini, S. Leoncini, A. Pecorelli, L. Ciccoli, F. Scalabrì, F. Marracino, M. Madonna, G. Belmonte, L. Ricceri, B. De Filippis, G. Laviola, G. Valacchi, T. Durand, J.M. Galano, C. Oger, A. Guy, V. Bultel-Poncé, 
J. Guy, S. Filosa, J. Hayek, M. D'Esposito, Oxidative brain damage in Mecp2mutant murine models of Rett syndrome, Neurobiol. Dis. 68 (2014) 66-77.

[36] A. Pecorelli, L. Ciccoli, C. Signorini, S. Leoncini, A. Giardini, M. D'Esposito, S. Filosa, J. Hayek, C. De Felice, G. Valacchi, Increased levels of 4HNE-protein plasma adducts in Rett syndrome, Clin. Biochem. 44 (5-6) (2011) 368-371.

[37] C. Signorini, C. De Felice, S. Leoncini, A. Giardini, M. D'Esposito, S. Filosa, F. Della Ragione, M. Rossi, A. Pecorelli, G. Valacchi, L. Ciccoli, J. Hayek, F-neuroprostanes mediate neurological severity in Rett syndrome, Clin. Chim. Acta 412 (1516) (2011) 1399-1406.

[38] S. Leoncini, C. De Felice, C. Signorini, A. Pecorelli, T. Durand, G. Valacchi, L. Ciccoli, J. Hayek, Oxidative stress in Rett syndrome: natural history, genotype, and variants, Redox Rep. 16 (4) (2011) 145-153.

[39] E. Grillo, C. Lo Rizzo, L. Bianciardi, V. Bizzarri, M. Baldassarri, O. Spiga, S. Furini, C. De Felice, C. Signorini, S. Leoncini, A. Pecorelli, L. Ciccoli, M.A. Mencarelli, J. Hayek, I. Meloni, F. Ariani, F. Mari, A. Renieri, Revealing the complexity of a monogenic disease: rett syndrome exome sequencing, PLoS One 8 (2) (2013) e56599.

[40] D.D. Armstrong, The neuropathology of the Rett syndrome, Brain Dev. 14 (1992) S89-S98.

[41] M. Müller, K. Can, Aberrant redox homoeostasis and mitochondrial dysfunction in Rett syndrome, Biochem. Soc. Trans. 42 (4) (2014) 959-964.

[42] D. Valenti, L. de Bari, B. De Filippis, A. Henrion-Caude, R.A. Vacca, Mitochondrial dysfunction as a central actor in intellectual disability-related diseases: an overview of Down syndrome, autism, Fragile X and Rett syndrome, Neurosci. Biobehav. Rev. 46 (Pt 2) (2014) 202-217.

[43] T.C. Theoharides, M. Athanassiou, S. Panagiotidou, R. Doyle, Dysregulated brain immunity and neurotrophin signaling in Rett syndrome and autism spectrum disorders, J. Neuroimmunol. 279 (2015) 33-38.

[44] C. Cervellati, C. Sticozzi, A. Romani, G. Belmonte, D. De Rasmo, A. Signorile, F. Cervellati, C. Milanese, P.G. Mastroberardino, A. Pecorelli, V. Savelli, H.J. Forman, J. Hayek, G. Valacchi, Impaired enzymatic defensive activity, mitochondrial dysfunction and proteasome activation are involved in RTT cell oxidative damage, Biochim. Biophys. Acta 1852 (10 Pt A) (2015) 2066-2074.

[45] M. Philippart, Clinical recognition of Rett syndrome, Am. J. Med. Genet. Suppl. 1 (1986) 111-118.

[46] O. Eeg-Olofsson, A.G. al-Zuhair, A.S. Teebi, M.M. al-Essa, Abnormal mitochondria in the Rett syndrome, Brain Dev. 10 (4) (1988) 260-262.

[47] O. Eeg-Olofsson, A.G. al-Zuhair, A.S. Teebi, M.M. al-Essa, Rett syndrome: genetic clues based on mitochondrial changes in muscle, Am. J. Med. Genet. 32 (1) (1989) $142-144$.

[48] O. Eeg-Olofsson, A.G. al-Zuhair, A.S. Teebi, A.S. Daoud, M. Zaki, M.S. Besisso, M.M. Al-Essa, Rett syndrome: a mitochondrial disease?, J. Child Neurol. 5 (3) (1990) 210-214.

[49] A. Ruch, T.W. Kurczynski, M.E. Velasco, Mitochondrial alterations in Rett syndrome, Pediatr. Neurol. 5 (5) (1989) 320-323.

[50] S. Wakai, K. Kameda, Y. Ishikawa, S. Miyamoto, M. Nagaoka, M. Okabe, R. Minami, N. Tachi, Rett syndrome: findings suggesting axonopathy and mitochondrial abnormalities, Pediatr. Neurol. 6 (5) (1990) 339-343.

[51] K. Jellinger, W. Grisold, D. Armstrong, A. Rett, Peripheral nerve involvement in the Rett syndrome, Brain Dev. 12 (1) (1990) 109-114.

[52] M.T. Dotti, L. Manneschi, A. Malandrini, N. De Stefano, F. Caznerale, A. Federico, Mitochondrial dysfunction in Rett syndrome. An ultrastructural and biochemical study, Brain Dev. 15 (2) (1993) 103-106.

[53] S.C. Mak, C.S. Chi, C.H. Chen, W.J. Shian, Abnormal mitochondria in Rett syndrome: one case report, Zhonghua Yi Xue Za Zhi 52 (2) (1993) 116-119.

[54] M.E. Cornford, M. Philippart, B. Jacobs, A.B. Scheibel, H.V. Vinters, Neuropathology of Rett syndrome: case report with neuronal and mitochondrial abnormalities in the brain, J. Child Neurol. 9 (4) (1994) 424-431.

[55] E. Cardaioli, M.T. Dotti, G. Hayek, M. Zappella, A. Federico, Studies on mitochondrial pathogenesis of Rett syndrome: ultrastructural data from skin and muscle biopsies and mutational analysis at mtDNA nucleotides 10463 and 2835, J. Submicrosc. Cytol. Pathol. 31 (2) (1999) 301-304.

[56] A. Pecorelli, F. Cervellati, G. Belmonte, G. Montagner, P. Waldon, J. Hayek, R. Gambari, G. Valacchi, Cytokines profile and peripheral blood mononuclear cells morphology in Rett and autistic patients, Cytokine 77 (2016) 180-188.

[57] P.V. Belichenko, E.E. Wright, N.P. Belichenko, E. Masliah, H.H. Li, W.C. Mobley, U. Francke, Widespread changes in dendritic and axonal morphology in Mecp2mutant mouse models of Rett syndrome: evidence for disruption of neuronal networks, J. Comp. Neurol. 514 (3) (2009) 240-258.

[58] M.J. Park, S. Aja, Q. Li, A.L. Degano, J. Penati, J. Zhuo, C.R. Roe, G.V. Ronnett, Anaplerotic triheptanoin diet enhances mitochondrial substrate use to remodel the metabolome and improve lifespan, motor function, and sociability in MeCP2-null mice, PLoS One 9 (10) (2014) e109527.

[59] L.W. Jin, M. Horiuchi, H. Wulff, X.B. Liu, G.A. Cortopassi, J.D. Erickson, I. Maezawa, Dysregulation of glutamine transporter SNAT1 in Rett syndrome microglia: a mechanism for mitochondrial dysfunction and neurotoxicity, $\mathrm{J}$ Neurosci. 35 (6) (2015) 2516-2529.

[60] S.B. Coker, A.R. Melnyk, Rett syndrome and mitochondrial enzyme deficiencies, J. Child Neurol. 6 (2) (1991) 164-166.

[61] H.A. Heilstedt, M.D. Shahbazian, B. Lee, Infantile hypotonia as a presentation of Rett syndrome, Am. J. Med. Genet. 111 (3) (2002) 238-242.

[62] S. Kriaucionis, A. Paterson, J. Curtis, J. Guy, N. Macleod, A. Bird, Gene expression analysis exposes mitochondrial abnormalities in a mouse model of Rett syndrome, Mol. Cell Biol. 26 (13) (2006) 5033-5042.

[63] V. Saywell, A. Viola, S. Confort-Gouny, Y. Le Fur, L. Villard, P.J. Cozzone, Brain magnetic resonance study of Mecp2 deletion effects on anatomy and metabolism,
Biochem Biophys. Res. Commun. 340 (3) (2006) 776-783.

[64] J.H. Gibson, B. Slobedman, K N H, S.L. Williamson, D. Minchenko, A. El-Osta, J.L. Stern, J. Christodoulou, Downstream targets of methyl CpG binding protein 2 and their abnormal expression in the frontal cortex of the human Rett syndrome brain, BMC Neurosci. 11 (2010) 53.

[65] E. Großer, U. Hirt, O.A. Janc, C. Menzfeld, M. Fischer, B. Kempkes, S. Vogelgesang, T.U. Manzke, L. Opitz, G. Salinas-Riester, M. Müller, Oxidative burden and mitochondrial dysfunction in a mouse model of Rett syndrome, Neurobiol. Dis. 48 (1) (2012) 102-114.

[66] W.A. Gold, S.L. Williamson, S. Kaur, I.P. Hargreaves, J.M. Land, G.J. Pelka, P.P. Tam, J. Christodoulou, Mitochondrial dysfunction in the skeletal muscle of a mouse model of Rett syndrome (RTT): implications for the disease phenotype, Mitochondrion 15 (2014) 10-17.

[67] B. De Filippis, D. Valenti, L. de Bari, D. De Rasmo, M. Musto, A. Fabbri, L. Ricceri, C. Fiorentini, G. Laviola, R.A. Vacca, Mitochondrial free radical overproduction due to respiratory chain impairment in the brain of a mouse model of Rett syndrome: protective effect of CNF1, Free Radic. Biol. Med. 83 (2015) 167-177.

[68] B. De Filippis, D. Valenti, V. Chiodi, A. Ferrante, L. de Bari, C. Fiorentini, M.R. Domenici, L. Ricceri, R.A. Vacca, A. Fabbri, G. Laviola, Modulation of Rho GTPases rescues brain mitochondrial dysfunction, cognitive deficits and aberrant synaptic plasticity in female mice modeling Rett syndrome, Eur. Neuropsychopharmacol. 25 (6) (2015) 889-901.

[69] A. Pecorelli, G. Leoni, F. Cervellati, R. Canali, C. Signorini, S. Leoncini, A. Cortelazzo, C. De Felice, L. Ciccoli, J. Hayek, G. Valacchi, Genes related to mitochondrial functions, protein degradation, and chromatin folding are differentially expressed in lymphomonocytes of Rett syndrome patients, Mediat. Inflamm. 2013 (2013) 137629.

[70] E. Sofić, P. Riederer, W. Killian, A. Rett, Reduced concentrations of ascorbic acid and glutathione in a single case of Rett syndrome: a postmortem brain study, Brain Dev. 9 (5) (1987) 529-531.

[71] P. Formichi, C. Battisti, M.T. Dotti, G. Hayek, M. Zappella, A. Federico, Vitamin E serum levels in Rett syndrome, J. Neurol. Sci. 156 (2) (1998) 227-230.

[72] C. Signorini, S. Leoncini, C. De Felice, A. Pecorelli, I. Meloni, F. Ariani, F. Mari, S. Amabile, E. Paccagnini, M. Gentile, G. Belmonte, G. Zollo, G. Valacchi, T. Durand, J.M. Galano, L. Ciccoli, A. Renieri, J. Hayek, Redox imbalance and morphological changes in skin fibroblasts in typical Rett syndrome, Oxid. Med. Cell Longev. 2014 (2014) 195935.

[73] L. Ciccoli, C. De Felice, E. Paccagnini, S. Leoncini, A. Pecorelli, C. Signorini, G. Belmonte, G. Valacchi, M. Rossi, J. Hayek, Morphological changes and oxidative damage in Rett Syndrome erythrocytes, Biochim. Biophys. Acta 1820 (4) (2012) 511-520.

[74] K. Szczesna, O. de la Caridad, P. Petazzi, M. Soler, L. Roa, M.A. Saez, S. Fourcade, A. Pujol, R. Artuch-Iriberri, M. Molero-Luis, A. Vidal, D. Huertas, M. Esteller, Improvement of the Rett syndrome phenotype in a MeCP2 mouse model upon treatment with levodopa and a dopa-decarboxylase inhibitor, Neuropsychopharmacology 39 (12) (2014) 2846-2856.

[75] C. Sierra, M.A. Vilaseca, N. Brandi, R. Artuch, A. Mira, M. Nieto, M. Pineda, Oxidative stress in Rett syndrome, Brain Dev. 23 (Suppl. 1) (2001) S236-S239.

[76] M. Pintaudi, E. Veneselli, A. Voci, A. Vignoli, D. Castiglione, M.G. Calevo, E. Grasselli, M. Ragazzoni, F. Cogliati, L. Calzari, G.F. Scornavacca, S. Russo, L. Vergani, Blood oxidative stress and metallothionein expression in Rett syndrome: probing for markers, World J. Biol. Psychiatry 17 (3) (2016) 198-209.

[77] C. Colantuoni, O.H. Jeon, K. Hyder, A. Chenchik, A.H. Khimani, V. Narayanan, E.P. Hoffman, W.E. Kaufmann, S. Naidu, J. Pevsner, Gene expression profiling in postmortem Rett syndrome brain: differential gene expression and patient classification, Neurobiol. Dis. 8 (5) (2001) 847-865.

[78] A. Benedetti, M. Comporti, H. Esterbauer, Identification of 4-hydroxynonenal as a cytotoxic product originating from the peroxidation of liver microsomal lipids, Biochim. Biophys. Acta 620 (2) (1980) 281-296.

[79] M. Comporti, Lipid peroxidation and biogenic aldehydes: from the identification of 4-hydroxynonenal to further achievements in biopathology, Free Radic. Res. 28 (6) (1998) 623-635.

[80] J.D. Morrow, K.E. Hill, R.F. Burk, T.M. Nammour, K.F. Badr, L.J. Roberts 2nd, A series of prostaglandin F2-like compounds are produced in vivo in humans by a non-cyclooxygenase, free radical-catalyzed mechanism, Proc. Natl. Acad. Sci. USA 87 (23) (1990) 9383-9387.

[81] E. Niki, Lipid peroxidation: physiological levels and dual biological effects, Free Radic. Biol. Med. 47 (5) (2009) 469-484.

[82] H. Esterbauer, R.J. Schaur, H. Zollner, Chemistry and biochemistry of 4-hydroxynonenal, malonaldehyde and related aldehydes, Free Radic. Biol. Med. 11 (1) (1991) 81-128.

[83] H. Esterbauer, Cytotoxicity and genotoxicity of lipid-oxidation products, Am. J Clin. Nutr. 57 (5 Suppl) (1993) 779S-785S (discussion 785S-786S).

[84] K. Uchida, 4-Hydroxy-2-nonenal: a product and mediator of oxidative stress, Prog. Lipid Res. 42 (4) (2003) 318-343.

[85] N. Zarkovic, 4-hydroxynonenal as a bioactive marker of pathophysiological processes, Mol. Asp. Med. 24 (4-5) (2003) 281-291.

[86] W. Łuczaj, A. Gęgotek, E. Skrzydlewska, Antioxidants and HNE in redox homeostasis, Free Radic. Biol. Med. (2016). http://dx.doi.org/10.1016/j.freeradbiomed.2016.11.033 This issue.

[87] G. Poli, R.J. Schaur, 4-Hydroxynonenal in the pathomechanisms of oxidative stress, IUBMB Life 50 (4-5) (2000) 315-321.

[88] G. Poli, R.J. Schaur, W.G. Siems, G. Leonarduzzi, 4-hydroxynonenal: a membrane lipid oxidation product of medicinal interest, Med. Res. Rev. 28 (4) (2008) 569-631.

[89] C. Signorini, C. De Felice, T. Durand, C. Oger, J.M. Galano, S. Leoncini, 
A. Pecorelli, G. Valacchi, L. Ciccoli, J. Hayek, Isoprostanes and 4-hydroxy-2nonenal: markers or mediators of disease? Focus on Rett syndrome as a model of autism spectrum disorder, Oxid. Med. Cell Longev. 2013 (2013) 343824.

[90] E.E. Dubinina, V.A. Dadali, Role of 4-hydroxy-trans-2-nonenal in cell functions, Biochemistry 75 (9) (2010) 1069-1087.

[91] H. Zhang, H.J. Forman, 4-hydroxynonenal-mediated signaling and aging, Free Radic. Biol. Med. (2016). http://dx.doi.org/10.1016/j.freeradbiomed.2016.11.032 This issue.

[92] F. Di Domenico, A. Tramutola, D.A. Butterfield, Role of 4-hydroxy-2-nonenal (HNE) in the pathogenesis of alzheimer disease and other selected age-related neurodegenerative disorders, Free Radic. Biol. Med. (2016). http://dx.doi.org/ 10.1016/j.freeradbiomed.2016.10.490 This issue.

[93] E. Barone, E. Head, D.A. Butterfield, M. Perluigi, HNE-modified proteins in Down syndrome: involvement in development of Alzheimer disease neuropathology, Free Radic. Biol. Med. (2016). http://dx.doi.org/10.1016/j.freeradbiomed.2016.10.508.

[94] G. Poli, F. Biasi, G. Leonarduzzi, 4-Hydroxynonenal-protein adducts: a reliable biomarker of lipid oxidation in liver diseases, Mol. Asp. Med. 29 (1-2) (2008) $67-71$.

[95] H. Zhong, H. Yin, Role of lipid peroxidation derived 4-hydroxynonenal (4-HNE) in cancer: focusing on mitochondria, Redox Biol. 4 (2015) 193-199.

[96] I. Rahman, A.A. van Schadewijk, A.J. Crowther, P.S. Hiemstra, J. Stolk, W. MacNee, W.I. De Boer, 4-Hydroxy-2-nonenal, a specific lipid peroxidation product, is elevated in lungs of patients with chronic obstructive pulmonary disease, Am. J. Respir. Crit. Care Med. 166 (4) (2002) 490-495.

[97] G. Leonarduzzi, E. Chiarpotto, F. Biasi, G. Poli, 4-Hydroxynonenal and cholesterol oxidation products in atherosclerosis, Mol. Nutr. Food Res. 49 (11) (2005) 1044-1049.

[98] V.R. Mali, S.S. Palaniyandi, Regulation and therapeutic strategies of 4-hydroxy-2nonenal metabolism in heart disease, Free Radic. Res. 48 (3) (2014) 251-263.

[99] T. Grune, P. Michel, N. Sitte, W. Eggert, H. Albrecht-Nebe, H. Esterbauer, W.G. Siems, Increased levels of 4-hydroxynonenal modified proteins in plasma of children with autoimmune diseases, Free Radic. Biol. Med. 23 (3) (1997) 357-360.

[100] A. Pecorelli, S. Leoncini, C. De Felice, C. Signorini, C. Cerrone, G. Valacchi, L. Ciccoli, J. Hayek, Non-protein-bound iron and 4-hydroxynonenal protein adducts in classic autism, Brain Dev. 35 (2) (2013) 146-154.

[101] L. Ciccoli, C. De Felice, E. Paccagnini, S. Leoncini, A. Pecorelli, C. Signorini, G. Belmonte, R. Guerranti, A. Cortelazzo, M. Gentile, G. Zollo, T. Durand, G. Valacchi, M. Rossi, J. Hayek, Erythrocyte shape abnormalities, membrane oxidative damage, and $\beta$-actin alterations: an unrecognized triad in classical autism, Mediat. Inflamm. 2013 (2013) 432616.

[102] Y. Zhang, Y. Sun, F. Wang, Z. Wang, Y. Peng, R. Li, Downregulating the canonical Wnt/ $\beta$-catenin signaling pathway attenuates the susceptibility to autism-like phenotypes by decreasing oxidative stress, Neurochem. Res. 37 (7) (2012) 1409-1419.

[103] A.K. Percy, Rett syndrome: exploring the autism link, Arch. Neurol. 68 (8) (2011) 985-989.

[104] M.A. Ross, Could oxidative stress be a factor in neurodevelopmental disorders?, Prostaglandins Leukot. Ess. Fat. Acids 63 (2000) 61-63.

[105] C. Sticozzi, G. Belmonte, A. Pecorelli, F. Cervellati, S. Leoncini, C. Signorini, L. Ciccoli, C. De Felice, J. Hayek, G. Valacchi, Scavenger receptor B1 posttranslational modifications in Rett syndrome, FEBS Lett. 587 (14) (2013) 2199-2204.

[106] A. Cortelazzo, C. De Felice, A. Pecorelli, G. Belmonte, C. Signorini, S. Leoncini, G. Zollo, A. Capone, C.D. Giovampaola, C. Sticozzi, G. Valacchi, L. Ciccoli, R. Guerranti, J. Hayek, Beta-actin deficiency with oxidative posttranslational modifications in Rett syndrome erythrocytes: insights into an altered cytoskeletal organization, PLoS One 9 (3) (2014) e93181.

[107] A. Pecorelli, G. Belmonte, I. Meloni, F. Cervellati, C. Gardi, C. Sticozzi, C. De Felice, C. Signorini, A. Cortelazzo, S. Leoncini, L. Ciccoli, A. Renieri, H. Jay Forman, J. Hayek, G. Valacchi, Alteration of serum lipid profile, SRB1 loss, and impaired Nrf2 activation in CDKL5 disorder, Free Radic. Biol. Med. 86 (2015) $156-165$.

[108] A. Pecorelli, C. Cervellati, A. Cortelazzo, F. Cervellati, C. Sticozzi, C. Mirasole R. Guerranti, A. Trentini, L. Zolla, V. Savelli, J. Hayek, G. Valacchi, Proteomic analysis of 4-hydroxynonenal and nitrotyrosine modified proteins in RTT fibroblasts, Int. J. Biochem. Cell Biol. (2016).

[109] B.S. Berlett, E.R. Stadtman, Protein oxidation in aging, disease and oxidative stress, J. Biol. Chem. 272 (1997) 20313-20316.

[110] A. Höhn, T. Jung, T. Grune, Pathophysiological importance of aggregated damaged proteins, Free Radic. Biol. Med. 71 (2014) 70-89.

[111] B. Friguet, L.I. Szweda, Inhibition of the multicatalytic proteinase (proteasome) by 4-hydroxy-2-nonenal cross-linked protein, FEBS Lett. 405 (1) (1997) 21-25.

[112] T. Grune, K.J. Davies, The proteasomal system and HNE-modified proteins, Mol Asp. Med. 24 (4-5) (2003) 195-204.

[113] G.L. Milne, Q. Dai, L.J. Roberts 2nd, The isoprostanes-25 years later, Biochim. Biophys. Acta 1851 (4) (2015) 433-445. http://dx.doi.org/10.1016/j.bbalip.2014.10.007.

[114] C. De Felice, C. Signorini, T. Durand, C. Oger, A. Guy, V. Bultel-Poncé, J.M. Galano, L. Ciccoli, S. Leoncini, M. D'Esposito, S. Filosa, A. Pecorelli, G. Valacchi, J. Hayek, F2-dihomo-isoprostanes as potential early biomarkers of lipid oxidative damage in Rett syndrome, J. Lipid Res. 52 (12) (2011) 2287-2297. http://dx.doi.org/10.1194/jlr.P017798.

[115] S. Leoncini, C. De Felice, C. Signorini, G. Zollo, A. Cortelazzo, T. Durand, J.M. Galano, R. Guerranti, M. Rossi, L. Ciccoli, J. Hayek, Cytokine dysregulation in MECP2- and CDKL5-related Rett syndrome: relationships with aberrant redox homeostasis, inflammation, and $\omega-3$ PUFAs, Oxid. Med. Cell Longev. 2015 (2015) 421624

[116] F. Mari, S. Azimonti, I. Bertani, F. Bolognese, E. Colombo, R. Caselli, E. Scala, I. Longo, S. Grosso, C. Pescucci, F. Ariani, G. Hayek, P. Balestri, A. Bergo, G. Badaracco, M. Zappella, V. Broccoli, A. Renieri, C. Kilstrup-Nielsen, N. Landsberger, CDKL5 belongs to the same molecular pathway of MeCP2 and it is responsible for the early-onset seizure variant of Rett syndrome, Hum. Mol. Genet. 14 (14) (2005) 1935-1946.

[117] D. Carouge, L. Host, D. Aunis, J. Zwiller, P. Anglard, CDKL5 is a brain MeCP2 target gene regulated by DNA methylation, Neurobiol. Dis. 38 (3) (2010) 414-424.

[118] G. Poli, F. Biasi, E. Chiarpotto, M.U. Dianzani, A. De Luca, H. Esterbauer, Lipid peroxidation in human diseases: evidence of red cell oxidative stress after circulatory shock, Free Radic. Biol. Med. 6 (2) (1989) 167-170.

[120] P.K. Maurya, P. Kumar, P. Chandra, Biomarkers of oxidative stress in erythrocytes as a function of human age, World J. Method. 5 (4) (2015) 216-222.

[121] A. Cortelazzo, C. De Felice, R. Guerranti, R. Leoncini, A. Barducci, S. Leoncini, C. Signorini, G. Zollo, A. Pecorelli, A. Gagliardi, A. Armini, E. Paccagnini, M. Gentile, L. Bini, T. Durand, J.M. Galano, M. Rossi, L. Ciccoli, J. Hayek, Erythrocyte cytoskeletal-plasma membrane protein network in Rett syndrome: effects of $\omega-3$ polyunsaturated fatty acids, Curr. Proteom. 12 (2015) 217-226.

[122] G. Valacchi, C. Sticozzi, Y. Lim, A. Pecorelli, Scavenger receptor class B type I: a multifunctional receptor, Ann. NY Acad. Sci. 1229 (E1-7) (2011) 06205. http:// dx.doi.org/10.1111/j.1749-6632.2011 (x).

[123] M.J. Justice, C.M. Buchovecky, S.M. Kyle, A. Djukic, A role for metabolism in Ret syndrome pathogenesis: new clinical findings and potential treatment targets, Rare Dis. 1 (2013) e27265.

[124] C.M. Buchovecky, S.D. Turley, H.M. Brown, S.M. Kyle, J.G. McDonald, B. Liu, A.A. Pieper, W. Huang, D.M. Katz, D.W. Russell, J. Shendure, M.J. Justice, A suppressor screen in Mecp2 mutant mice implicates cholesterol metabolism in Rett syndrome, Nat. Genet. 45 (9) (2013) 1013-1020.

[125] G. Nagy, S.L. Ackerman, Cholesterol metabolism and Rett syndrome pathogenesis, Nat. Genet. 45 (9) (2013) 965-967.

[126] J.V. Patankar, Cholesterol metabolism is a potential therapeutic target for Rett syndrome, Clin. Genet. 85 (3) (2014) 229-230.

[127] M. Segatto, L. Trapani, I. Di Tunno, C. Sticozzi, G. Valacchi, J. Hayek, V. Pallottini, Cholesterol metabolism is altered in Rett syndrome: a study on plasma and primary cultured fibroblasts derived from patients, PLoS One 9 (8) (2014) e104834.

[128] A.M. Lopez, J.C. Chuang, K.S. Posey, S.D. Turley, Suppression of brain cholestero synthesis in male Mecp2-deficient mice is age dependent and not accompanied by a concurrent change in the rate of fatty acid synthesis, Brain Res. 1654 (Pt A) (2017) 77-84.

[129] S.K. Niture, R. Khatri, A.K. Jaiswal, Regulation of Nrf2-an update, Free Radic. Biol. Med. 66 (2014) 36-44.

[130] K.M. Huber, E. Klann, M. Costa-Mattioli, R.S. Zukin, Dysregulation of mammalian target of rapamycin signaling in mouse models of autism, J. Neurosci. 35 (41) (2015) 13836-13842.

[131] S. Ricciardi, E.M. Boggio, S. Grosso, G. Lonetti, G. Forlani, G. Stefanelli, E. Calcagno, N. Morello, N. Landsberger, S. Biffo, T. Pizzorusso, M. Giustetto, $\mathrm{V}$. Broccoli, Reduced AKT/mTOR signaling and protein synthesis dysregulation in a Rett syndrome animal model, Hum. Mol. Genet. 20 (6) (2011) 1182-1196.

[132] K. Tsujimura, K. Irie, H. Nakashima, Y. Egashira, Y. Fukao, M. Fujiwara, M. Itoh, M. Uesaka, T. Imamura, Y. Nakahata, Y. Yamashita, T. Abe, S. Takamori, K. Nakashima, miR-199a links MeCP2 with mTOR signaling and its dysregulation leads to rett syndrome phenotypes, Cell Rep. 12 (11) (2015) 1887-1901.

[133] S. Rangasamy, S. Olfers, B. Gerald, A. Hilbert, S. Svejda, V. Narayanan, Reduced neuronal size and mTOR pathway activity in the Mecp2 A140V Rett syndrome mouse model, F1000Res, 5, 2016, 2269.

[134] G. Valacchi, C. Sticozzi, G. Belmonte, F. Cervellati, A. Pecorelli, C. Signorini, S. Leoncini, L. Ciccoli, C. De Felice, F. Della Ragione, F. Scalabri, F. Marracino, M. Madonna, M. D'Esposito, H. Joussef, F. Cervellati, F. Stefania, Scavenger Receptor B1 oxidative post-translational modifications are responsible for its loss in Rett syndrome, Free Radic. Biol. Med. 75 (Suppl. 1) (2014) S10-S11.

[135] M. Mangatt, K. Wong, B. Anderson, A. Epstein, S. Hodgetts, H. Leonard, J. Downs, Prevalence and onset of comorbidities in the CDKL5 disorder differ from Rett syndrome, Orphanet J. Rare Dis. 11 (2016) 39.

[136] W.E. Kaufmann, S. Naidu, J. Pevsner, Gene expression profiling in postmortem Rett Syndrome brain: differential gene expression and patient classification, Neurobiol. Dis. 8 (5) (2001) 847-865.

[137] M. Perluigi, R. Sultana, G. Cenini, F. Di Domenico, M. Memo, W.M. Pierce, R. Coccia, D.A. Butterfield, Redox proteomics identification of 4-hydroxynonenalmodified brain proteins in Alzheimer's disease: role of lipid peroxidation in Alzheimer's disease pathogenesis, Proteom. Clin. Appl. 3 (6) (2009) 682-693.

[138] F. Di Domenico, G. Pupo, A. Tramutola, A. Giorgi, M.E. Schininà, R. Coccia, E. Head, D.A. Butterfield, M. Perluigi, Redox proteomics analysis of HNE-modified proteins in Down syndrome brain: clues for understanding the development of Alzheimer disease, Free Radic. Biol. Med. 71 (2014) 270-280. http://dx.doi.org/ 10.1016/j.freeradbiomed.2014.03.027.

[139] E. Barone, E. Head, D.A. Butterfield, M. Perluigi, 4HNE-modified proteins in Down syndrome: involvement in development of Alzheimer disease neuropathology, Free Radic. Biol. Med. (2016). http://dx.doi.org/10.1016/j.freeradbiomed.2016.10.508.

[140] L. Abuhatzira, R. Shemer, A. Razin, MeCP2 involvement in the regulation of neuronal alpha-tubulin production, Hum. Mol. Genet. 18 (8) (2009) 1415-1423.

[141] W.A. Gold, T.A. Lacina, L.C. Cantrill, J. Christodoulou, MeCP2 deficiency is associated with reduced levels of tubulin acetylation and can be restored using 
HDAC6 inhibitors, J. Mol. Med. 93 (1) (2015) 63-72.

[142] J. Nectoux, C. Florian, C. Delepine, N. Bahi-Buisson, M. Khelfaoui, S. Reibel, J. Chelly, T. Bienvenu, Altered microtubule dynamics in Mecp2-deficient astrocytes, J. Neurosci. Res. 90 (5) (2012) 990-998.

[143] C. Delépine, J. Nectoux, N. Bahi-Buisson, J. Chelly, T. Bienvenu, MeCP2 deficiency is associated with impaired microtubule stability, FEBS Lett. 587 (2) (2013) 245-253.

[144] C. Delépine, H. Meziane, J. Nectoux, M. Opitz, A.B. Smith, C. Ballatore, Y. Saillour, A. Bennaceur-Griscelli, Q. Chang, E.C. Williams, M. Dahan, A. Duboin, P. Billuart, Y. Herault, T. Bienvenu, Altered microtubule dynamics and vesicular transport in mouse and human MeCP2-deficient astrocytes, Hum. Mol. Genet. 25 (1) (2016) $146-157$.

[145] A. Bergo, M. Strollo, M. Gai, I. Barbiero, G. Stefanelli, S. Sertic, C. Cobolli Gigli, F. Di Cunto, C. Kilstrup-Nielsen, N. Landsberger, Methyl-CpG binding protein 2 (MeCP2) localizes at the centrosome and is required for proper mitotic spindle organization, J. Biol. Chem. 290 (6) (2015) 3223-3237.

[146] F. Stricher, C. Macri, M. Ruff, S. Muller, HSPA8/HSC70 chaperone protein: structure, function, and chemical targeting, Autophagy 9 (12) (2013) 1937-1954.

[147] C. Ezeonwuka, M. Rastegar, MeCP2-Related Diseases and Animal Models Diseases, 2, 2014, pp. 45-47.

[148] O.A. Janc, M. Müller, The free radical scavenger Trolox dampens neuronal hyperexcitability, reinstates synaptic plasticity, and improves hypoxia tolerance in a mouse model of Rett syndrome, Front Cell Neurosci. 8 (2014) 56. http:// dx.doi.org/10.3389/fncel.2014.00056.
[149] O.A. Janc, M.A. Hüser, K. Dietrich, B. Kempkes, C. Menzfeld, S. Hülsmann, M. Müller, Systemic radical scavenger treatment of a mouse model of rett syndrome: merits and limitations of the vitamin E derivative trolox, Front. Cell Neurosci. 10 (2016) 266.

[150] B.T. Kurien, K. Hensley, M. Bachmann, R.H. Scofield, Oxidatively modified autoantigens in autoimmune diseases, Free Radic. Biol. Med. 41 (4) (2006) $549-556$

[151] A. Cortelazzo, C. De Felice, R. Guerranti, C. Signorini, S. Leoncini, A. Pecorelli, G. Zollo, C. Landi, G. Valacchi, L. Ciccoli, L. Bini, J. Hayek, Subclinical inflammatory status in Rett syndrome, Mediat. Inflamm. 2014 (2014) 480980.

[152] A. Cortelazzo, C. de Felice, S. Leoncini, C. Signorini, R. Guerranti, R. Leoncini, A. Armini, L. Bini, L. Ciccoli, J. Hayek, Inflammatory protein response in CDKL5 Rett syndrome: evidence of a subclinical smouldering inflammation, Inflamm. Res. (2016).

[153] N.C. Derecki, J.C. Cronk, Z. Lu, E. Xu, S.B. Abbott, P.G. Guyenet, J. Kipnis, Wildtype microglia arrest pathology in a mouse model of Rett syndrome, Nature 484 (7392) (2012) 105-109. http://dx.doi.org/10.1038/nature10907.

[154] T.P. Klushnik, V.V. Gratchev, P.V. Belichenko, Brain-directed autoantibodies levels in the serum of Rett syndrome patients, Brain Dev. 23 (Suppl 1) (2001) S113-S117.

[155] V.T. Ramaekers, J.M. Sequeira, R. Artuch, N. Blau, T. Temudo, A. Ormazabal, M. Pineda, A. Aracil, F. Roelens, F. Laccone, E.V. Quadros, Folate receptor autoantibodies and spinal fluid 5-methyltetrahydrofolate deficiency in Ret syndrome, Neuropediatrics 38 (4) (2007) 179-183. 